\title{
Torque Control Strategy for an Axial Flux Switched Reluctance Machine
}

\author{
A. Egea, G. Ugalde, J. Poza \\ Machines and Automatics \\ Mondragon University-Faculty of Engineering \\ Arrasate-Mondragon, Spain \\ aegea@mondragon.edu
}

\begin{abstract}
This paper reflects the work done to design a torque control strategy for an axial flux switched reluctance machine. The general electrical model is first presented but as the switched reluctance machine behaves nonlinearly ${ }^{1}$ a (three-dimensional) finite element method characterization is performed, so the nonlinearity may be considered. Once the machine is characterized in FEM a Simulink model is developed where a torque control strategy is proposed. Then, both the machine and the control are experimentally tested. The control setting, and the obtained real performance results are also presented in this document. Finally, the most outstanding conclusions about the control strategy are captured. Main difficulties encountered during the implementation of the control strategy are also collected.
\end{abstract}

Keywords-Switched reluctance, Axial flux, FEM 3D, Electric Vehicle, Torque control.

\section{INTRODUCTION}

In the transition towards a new era of low-carbon society and climate resilient economy, one of the European Union's key policy objectives for the upcoming decades is cutting $60 \%$ of $\mathrm{CO} 2$ emissions from transport, where fossil fuel dependence is around 96\%. Electric vehicles (EV) are considered to be the most plausible alternative to fossil fuelbased road transport. There is a source of uncertainty related to the availability of reliable and diversified supply of metals to produce the necessary permanent magnets (PM) to assure high efficiency and high-power density electrical motors. The shift from a fossil fuel dependence scenario to a permanentmagnet dependence scenario (even more critical as they can only be found under single source monopolies) could limit significantly the large-scale introduction of EVs as PM based motors could not be supplied in adequate volumes at a competitive cost.

The research leading to these results has received funding from the European Union Seventh Framework Programme [FP7/2007-2013] under grant agreement $\mathrm{n}^{\circ} 605429$.
In this context, the development of high efficiency motors using magnet-free motor designs is crucial. A promising option for this new generation of electric motors could be reluctance technology: this kind of motors stands out for its wide constant power capability, reliability and security. However, it has been left out of the first line up to now due to its lower power density when compared to PM motors.

On the other hand, the use of axial-flux configurations has proved recently in PM motors that power density can be increased in a relatively cost-effective way.

VENUS European project Consortium is working in a design that combines both approaches, reluctance motors in axial-flux configuration, Axial Flux Switched Reluctance Motor (AFSR). The topology selected was first presented by Labak $[1,[2]$ and the designed motor for VENUS project will be constructed and integrated in an electric vehicle in the future.

Even if some authors proposed different analytical models for switched reluctance machines [[3[4], the intrinsic nonlinearity of this type of machines makes use of finite element almost unavoidable [5[6]. Once the machine is characterized by FEM tools may be simulated using Matlab Simulink [7[8].

The SRM machines by nature present a quite high torque ripple bringing a challenge for the definition of the control strategy in applications where this ripple may be critical. Different strategies have been proposed in the literature. For example, Dong-Hee Lee [9] presents an extended work about SRM control while Husain [10], gives a general view of SRM machine torque ripple minimization. Peter [11] and Lee [12] also give some notes for reduction of the torque ripple.

The torque control strategy for the designed machine is presented in this work. This control is separated in two different actions, one for low speed operation and the other for higher speed operation. The aim of using two different actions is to improve the driving experience but reducing the computational load of the control board. 


\section{Workshop on SRM drives an alternative for E-traction}

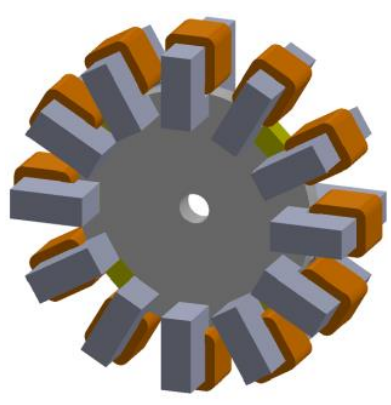

a)

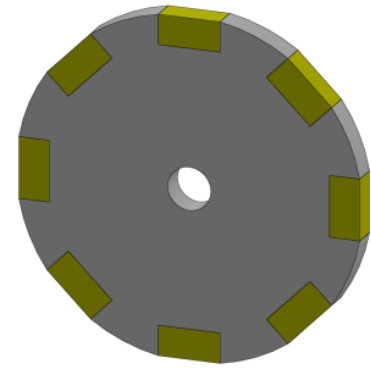

b)
Fig.1: a)Rotor and stator arrangement by using axial-flux configuration and $b$ ) rotor detail

\section{AXIAL-FLUX SWITCHED RELUCTANT MOTOR MODEL}

\section{A. Axial-Flux Switched Reluctant Motor}

Fig.1 shows the geometry of the AFSRM used in this work. The motor comprises a rotor disc carrying 8 rotor poles and 12 stator coil assemblies placed on the periphery of the rotor disc.

\section{B. Electrical Equations}

Usually a simplified model of the SRM motor is used, as assuming the non-linearity of the inductance is not so easy analytically. The main electrical equation of a SRM machine is the one described in (1) expression.

$$
V(t)=R_{p_{h} i} i(t)+\frac{d \psi\left(\theta_{x} i\right)}{d t}
$$

The voltage in each phase (V) is the sum of the voltage drop in the phase resistance $R_{p h}$ and the flux linkage derivative as a function of the position and the current. Due to the non-linearity of the inductance a simple mathematical expression cannot describe the current trajectory. Therefore, the flux linkage derivative can be split into two terms:

$$
\frac{d \psi(\theta, i)}{d t}=\frac{d \psi(\theta, i)}{d i} \frac{d i}{d t}+\frac{d \psi(\theta, i)}{d \theta} \frac{d \theta}{d t}
$$

The first term in (2) assumes the current time derivative and the inductance which is a function of the position and the current:

$$
\frac{d \psi(\theta, i)}{d i} \frac{d i}{d t}=L(\theta, i) \frac{d i}{d t}
$$

The second term in (2) is also known as the back emf. This emf is a function of the rotational speed, the current and the inductance change:

$$
e m f=\frac{d \psi(\theta, i)}{d \theta} \frac{d \theta}{d t}=\frac{d L(\theta, i)}{d \theta} \omega i(t)
$$

So, expression (1) can be rewritten as follows:

$$
V(t)=R_{p h i} i(t)+L(\theta, i) \frac{d i}{d t}+\frac{d L(\theta, i)}{d \theta} \omega i(t)
$$

Equation (5) shows clearly that a mathematical model of a SRM machine is not easy to develop. The evolution of the current is not an easy task to describe and neither the inductance value, as it is dependent of the current and the position.

\section{Torque Production}

In case of a linear machine, the inductance value has a trapezoidal shape as shown in Fig.2. Depending on the current activation moment the machine may work at motoring or regeneration. Ideally, the current is established instantaneously. If the current is activated while the inductance is increasing, so when the rotor pole is getting closer to the stator pole, the generated torque is positive. On contrary, when the rotor pole is moving from aligned to unaligned position the torque is negative.

This figure makes clear the importance of the current activation time. The maximum torque per phase is obtained if the current is activated just when the inductance starts increasing (unaligned position) and deactivated at maximum value of inductance (aligned position). In any other case the average torque will be decreased. If the current activation time is shorter the torque will decrease, while if it is longer negative torque will be produced. This all shows the importance of switching on and switching off the current at the right moment.

In case of a linear SRM machine, the torque can be expressed as:

$$
T_{\theta}=\frac{1}{2} i^{2} \frac{d L}{d \theta}
$$

This expression is only valid with a linear inductance. A general expression valid also in case of a non-linear inductance is when the electromagnetic torque is obtained from the coenergy, $\mathrm{W}^{\prime}$ :

$$
\mathrm{T}(\mathrm{t})=\frac{\mathrm{dW}}{d t}
$$

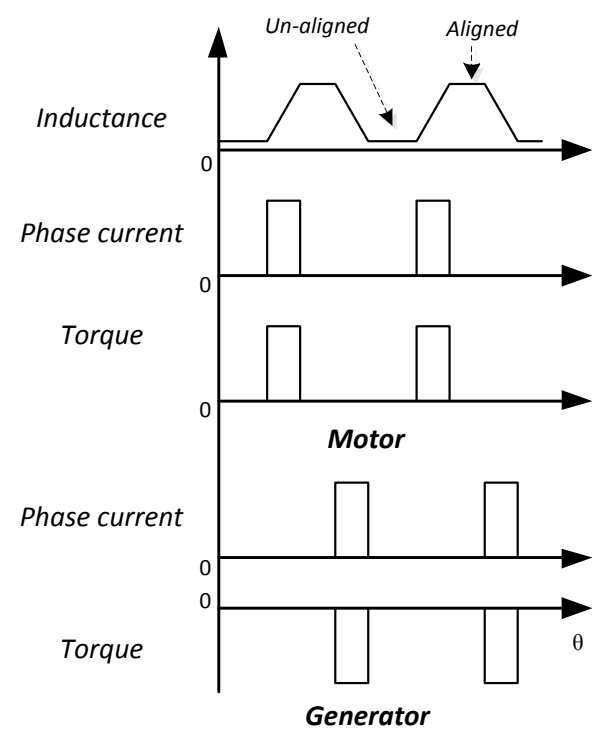

Fig.2: Inductance and torque profile [Peter 2013] 


\section{Workshop on SRM drives an alternative for E-traction}

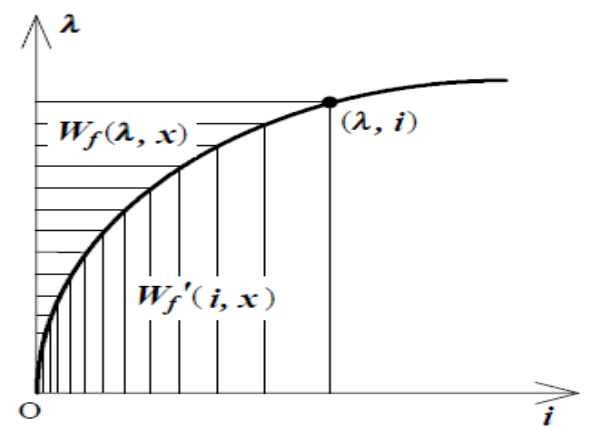

Fig.3: Energy and co-energy

The co-energy is the integration of the flux linkage along the current:

$$
W^{s}(\mathrm{I}, \mathrm{t})=\int_{0}^{i} \Psi\left(i_{0}, t\right) d i
$$

In Fig. 3 the energy and coenergy concept is explained in a graphical way. The shown flux linkage follows a non-linear behavior, which results in a higher mechanical energy than the energy storage in the inductance. In case of a linear inductance (flux linkage) both energies are equal making the expression (7) valid.

\section{Non-Linear model}

At the proposed SRM model the input of the machine is the stator voltage, while the outputs are the torque, position and speed. Integrating the input voltage, the flux in each phase is obtained. Having this flux and the rotor position it is possible to get the instantaneous current in each phase from tables calibrated previously with FEM simulation, analytical model or experimental result. A torque characteristic as function of the current and the rotor position must be also obtained. The electromagnetic torque is the input of the mechanical model from where the mechanical torque, speed and position are obtained.

In this project, the non-linear model is implemented in Matlab /Simulink. The electromagnetic model is based in a torque and current map. FEM-3D simulations are needed to get these torque vs. current and position and current vs. flux and position maps. Then including this maps in the electromagnetic model shown in Fig.5 it is possible to have a SRM machine model assuming the non-linearity.

The modularity of this motor topology makes phases to be magnetically decoupled, thus motor performance can be extrapolated from the analysis of one pole pair and considering the number of active phases and poles. As the motor has three-phases, only one of them should be simultaneously active to generate torque in one direction. With 12 stator poles in the motor, there are 4 poles per phase. Therefore, motor parameters (torque, losses, etc.) are 4 times higher than in one pole.

FEM-3D simulations get accurate curves of switched reluctance motor's characteristic (flux vs. current, and torque vs. position). In these FEM-3D magneto static simulations a unique $\mathrm{C}$-core together with three rotor poles is simulated. Three rotor poles are simulated so the influence of the adjacent poles in the flux lines can be considered. The coil in the $\mathrm{C}$-core is fed with different current levels and a movement from $0^{\circ}$ to $45^{\circ}$ is performed to take a complete torque cycle. From these simulations torque (Fig.4) and flux linkage curves are obtained so then dynamic simulations may be performed in Matlab Simulink software.

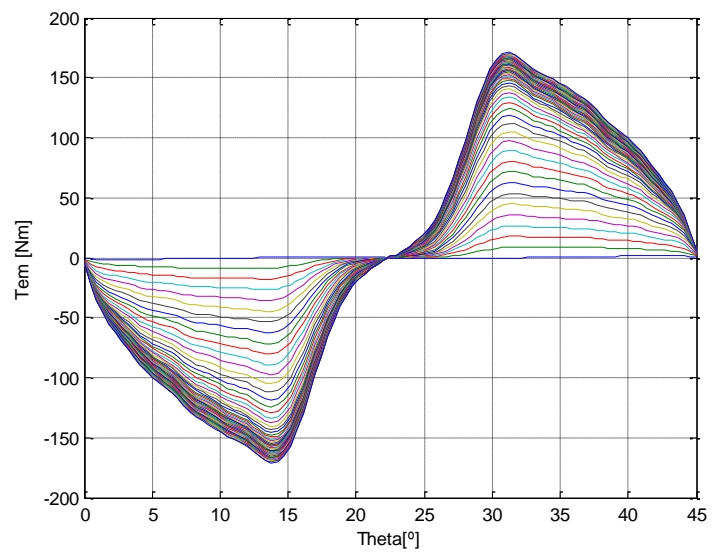

Fig.4: Torque vs. Current and position curves (Each curve corresponds to a current level, starting at $0 \mathrm{~A}$ and reaching 910A)

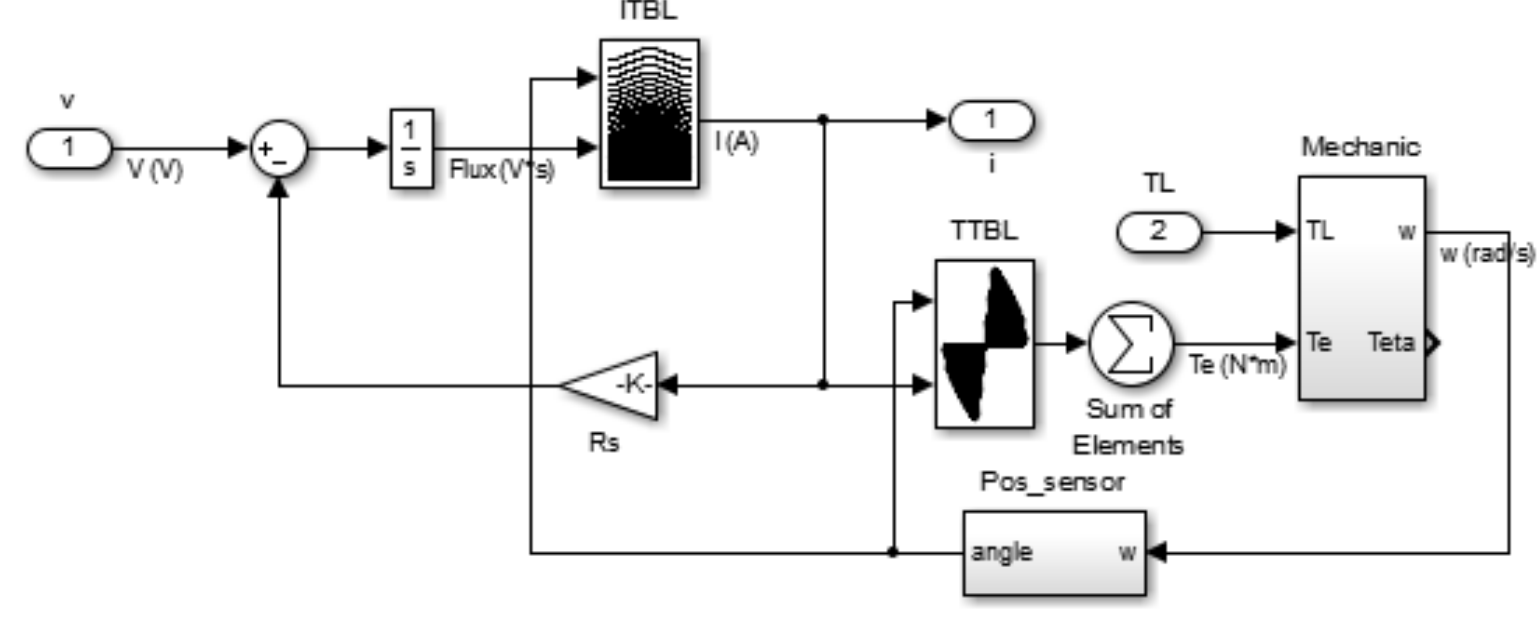

Fig.5: SRM Matlab-Simulink model 


\section{Workshop on SRM drives an alternative for E-traction}

\section{TORQUE CONTROL STRATEGY}

The general view of the system is shown in Fig. 6. The control is based on two main loops, the current and torque loops.

The current loop gives gate signals to the converter considering the current consign, the actual current and the activation/deactivation angles. A simple on/off control proves to be sufficient for the current loop.

The torque control generates the signals for the current control depending on the rotational speed, the torque consigns and the torque estimator. The proposed torque control strategy includes a direct torque control for higher speeds and a PI control for the lower speeds as shown in Fig. 7. The direct torque control is based in a previous characterization of the machine to get a characteristic function which gives the current consign depending on the speed and the torque consign. This control will give a constant current consign with which a main torque equal to the consign torque will be generated. However, the torque ripple is not controlled this way, and it could be quite dangerous when starting the vehicle in a slope. Due to the ripple a negative momentary negative torque may occur making the vehicle move in reverse direction. To avoid this problem along with uncomfortable vibrations a PI controller may be use at low speeds. The PI controller generates a current consign from the error between the torque consign and the real torque. As a torque sensor is not used the actual torque must be estimated using a torque estimator. This estimator is obtained when characterizing the machine. The torque is represented as a function of the currents and the position (Fig.4).

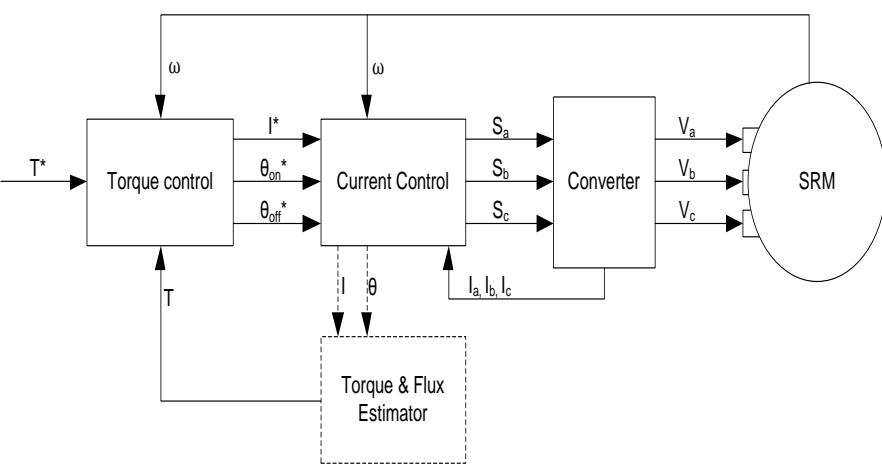

Fig. 6: Controlled SRM flow diagram

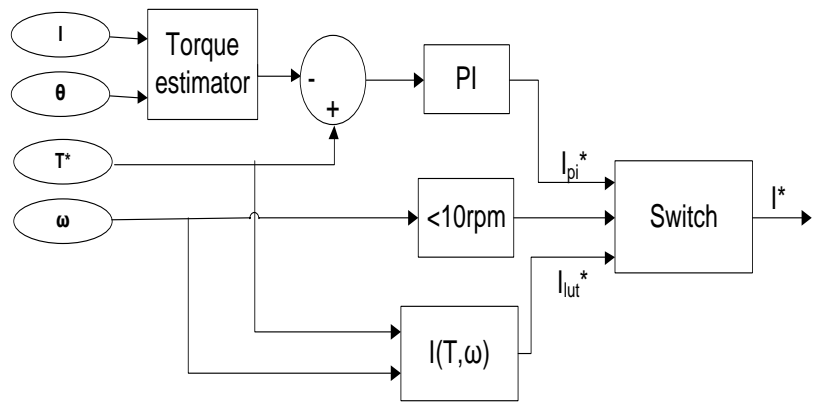

Fig. 7: Torque control strategy diagram
As explained before due to the impossibility to set the current instantaneously the dynamic performance of the AFSRM varies from the static one.

In static mode or with ideal square form current the maximum torque is obtained when the phase is activated from $22.5^{\circ}$ to $45^{\circ}$. However, the current needs some time to be established. The activation and deactivation signals must be given in advance, so the maximum possible torque is given. In Table I and Table II the optimal activation and deactivation angles are shown. As it can be deduced the higher the speed and the current are, more critical this phenomenon is. In Fig. 8 the maximum torque the machine gives depending on the speed and the current is shown. The torque generated by the machine is reduced markedly with increasing speed.

TABLE I:Phase Activation Angle depending on the speed and current

\begin{tabular}{|c|c|c|c|c|c|c|c|c|}
\hline Alrpm & $\mathbf{0}$ & 1000 & 2000 & 3000 & 4000 & 5000 & 6000 & 7000 \\
\hline 50 & 22,5 & 22,0 & 21,6 & 21,1 & 20,6 & 20,2 & 19,7 & 19,2 \\
\hline 150 & 22,5 & 21,0 & 19,5 & 18,0 & 16,5 & 15,0 & 13,5 & 12,0 \\
\hline 250 & 22,5 & 19,9 & 17,3 & 14,6 & 12,0 & 12,0 & 12,0 & 12,0 \\
\hline 350 & 22,5 & 19,5 & 16,5 & 13,5 & 12,0 & 12,0 & 12,0 & 12,0 \\
\hline 450 & 22,5 & 19,0 & 15,5 & 12,0 & 12,0 & 12,0 & 12,0 & 12,0 \\
\hline
\end{tabular}

TABle II: Phase DeACTIVATION ANGLE DEPENDING ON THE SPEED AND CURRENT

\begin{tabular}{|c|c|c|c|c|c|c|c|c|}
\hline A $\backslash \mathbf{r p m}$ & $\mathbf{0}$ & $\mathbf{1 0 0 0}$ & $\mathbf{2 0 0 0}$ & $\mathbf{3 0 0 0}$ & $\mathbf{4 0 0 0}$ & $\mathbf{5 0 0 0}$ & $\mathbf{6 0 0 0}$ & $\mathbf{7 0 0 0}$ \\
\hline $\mathbf{5 0}$ & 45,0 & 44,2 & 43,4 & 42,6 & 41,8 & 41,0 & 40,2 & 39,4 \\
\hline $\mathbf{1 5 0}$ & 45,0 & 43,2 & 41,4 & 39,6 & 37,8 & 36,0 & 36,0 & 36,0 \\
\hline $\mathbf{2 5 0}$ & 45,0 & 42,8 & 40,5 & 38,3 & 36,0 & 36,0 & 36,0 & 36,0 \\
\hline $\mathbf{3 5 0}$ & 45,0 & 42,4 & 39,9 & 37,3 & 36,0 & 36,0 & 36,0 & 36,0 \\
\hline $\mathbf{4 5 0}$ & 45,0 & 42,0 & 39,0 & 36,0 & 36,0 & 36,0 & 36,0 & 36,0 \\
\hline
\end{tabular}

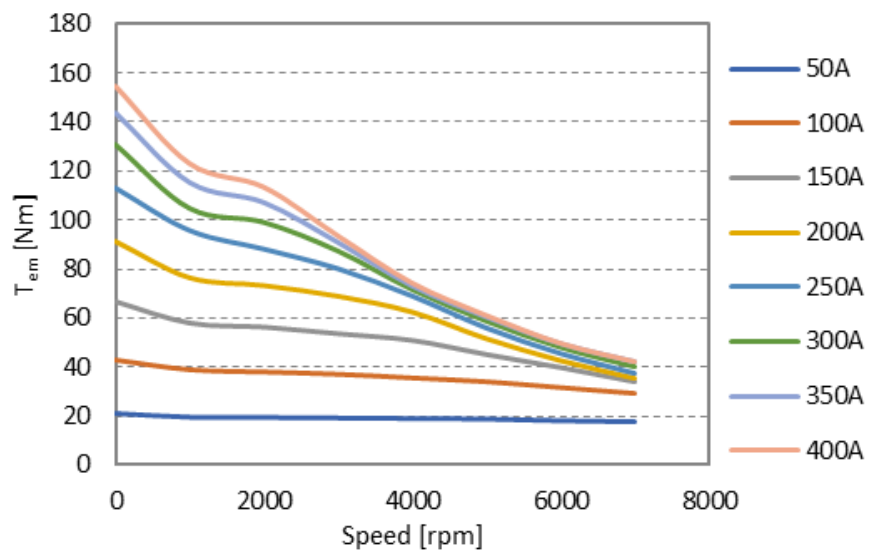

Fig. 8: Dynamic torque performance 


\section{Workshop on SRM drives an alternative for E-traction}

\section{MACHINE PERFORMANCE}

\section{A. Simulations}

To check the validity of the proposed method by simulations the machine is rotated at between 0 and $20 \mathrm{rpm}$ speed as defined in Fig. 9 while a constant torque consign of $48 \mathrm{Nm}$ is set. When the rotational speed is less than $10 \mathrm{rpm}$ a PI torque control is performed, while over this threshold the direct torque control is working obtaining the torque evolution shown in Fig. 10. It is easily noticeable how the torque ripple of $\pm 10 \mathrm{Nm}$ is eliminated when using the PI controller. This happens because the current consign is changing all the time when the PI is activated, while a constant current consign is generated with the direct torque controller as may be seen in Fig. 11.

The PI controller presents better performance in terms of torque ripple minimization and even following the torque consign. However, this is very dependent on the current reading sample time capability and the needs of the control board. Furthermore, using a PI controller the torque capability is reduced. So, the combination of control methods proposed in this work is considered a good option, where accuracy, behavior and computational speed are combined.

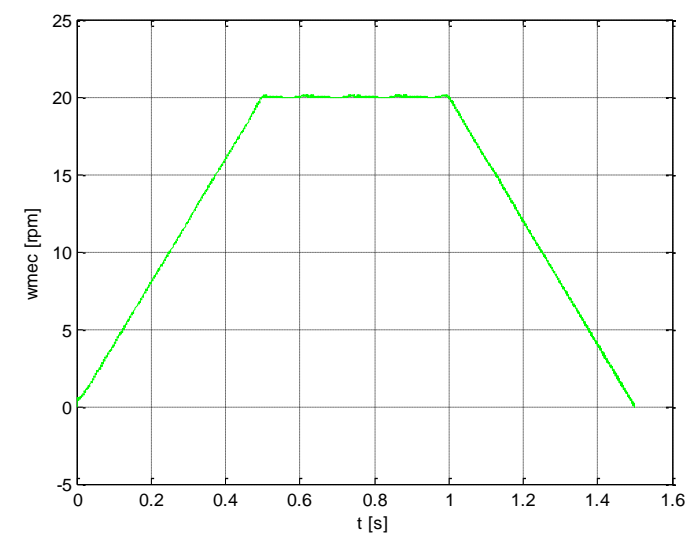

Fig. 9: Acceleration-deceleration speed profile

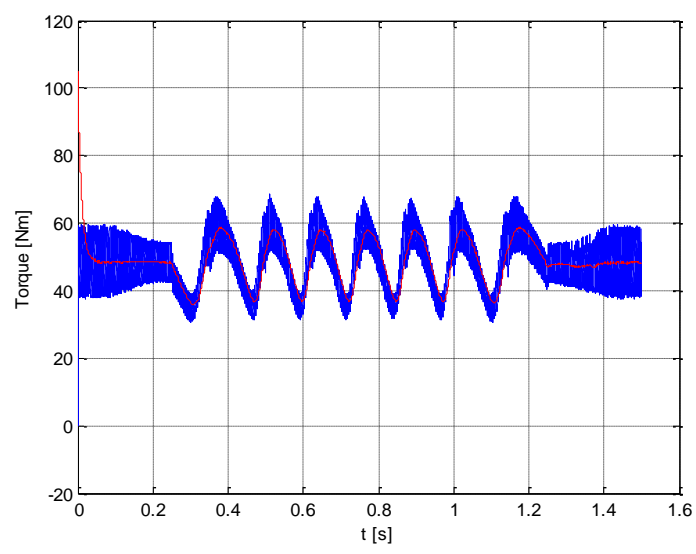

Fig. 10: Torque time wave

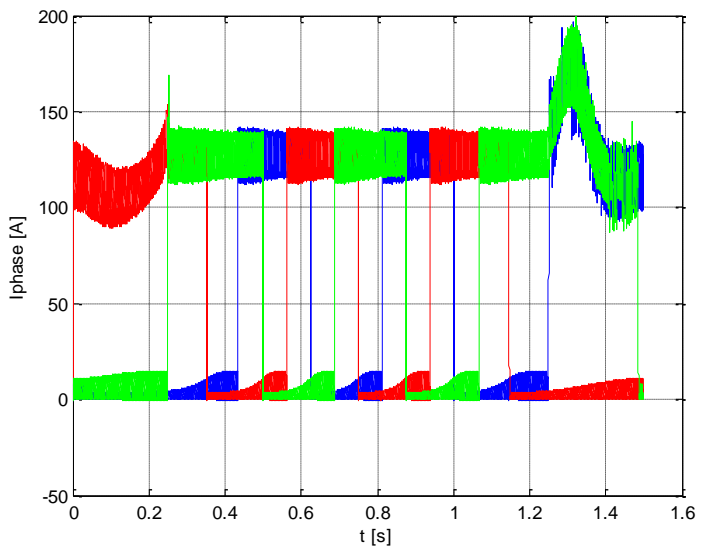

Fig. 11: Three phase current waves

B. Test Bench

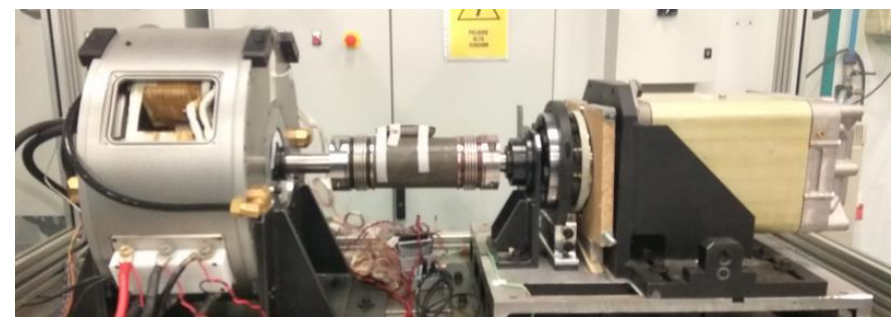

Fig. 12: Test Bench

After simulation, and once having the motor prototype experimental tests were carried on in the test bench shown in Fig. 12. First stall or static characteristic of the machine was obtained supplying the machine with a DC current supply. Then dynamic tests were done so both the machine dynamic performance and the control strategy were validated.

Fig. 13 shows the experimental test points of the Torque Vs current static characteristic of the VENUS motor. Due to the power limits of the DC current supply equipment, the maximum testing current level has been stablished at 130A.

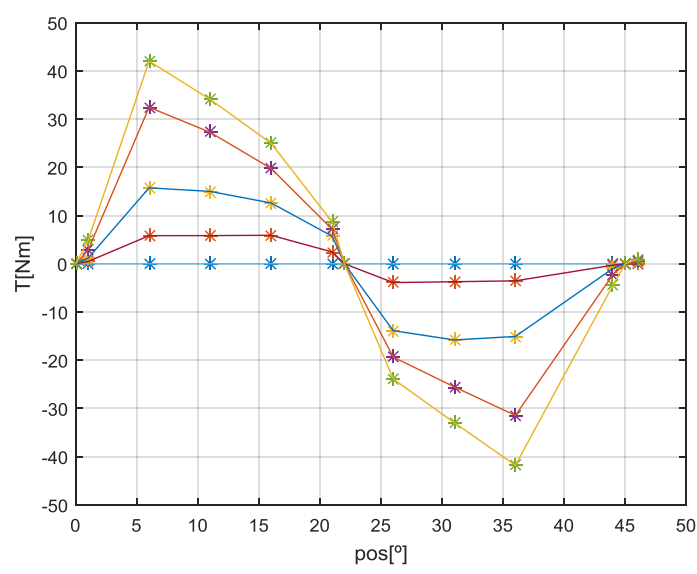

Fig. 13: Experimental points of Torque VS current static characteristic 


\section{Workshop on SRM drives an alternative for E-traction}

(Phase maximum current 130 Adc)
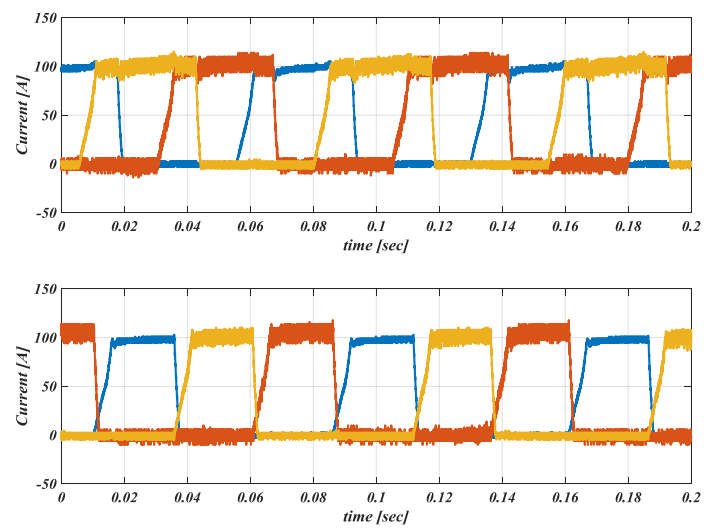

Fig. 14: Resulting currents of each phase for the case of $100 \mathrm{~A}$ controlled at both control modes, Overlapping and none overlapping

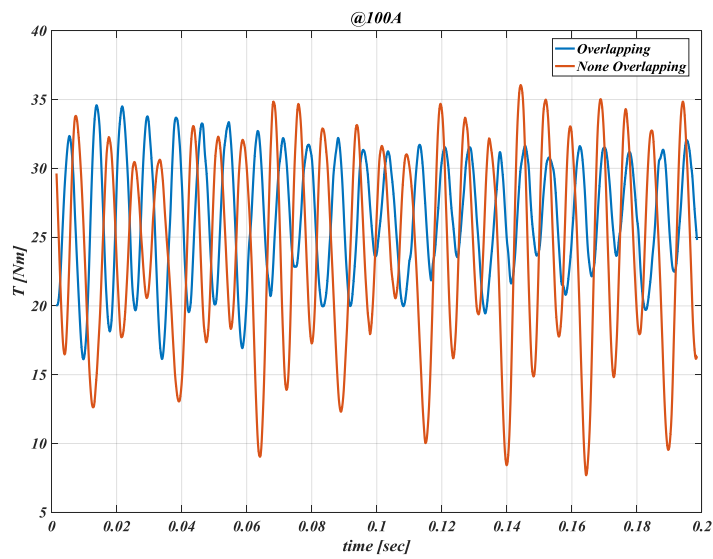

Fig. 15: Torque @ 100A, Overlapping and none overlapping

The first task to obtain the best dynamic performance of the machine is to compute turn ON/OFF angles at each current and speed working point. The main objective is to get the maximum torque possible at each current and speed reference point. It is also necessary to validate that the dynamic evolution of the phase currents is good. This is a key point to assure that the maximum peaks values do not go above the protection limits.

The optimization has been done for the two operation mode strategies, Fig. 14 and Fig. 15:

1. No overlapping Strategy: The phase currents do not have a common area of constant current value at top setpoint level.

2. Overlapping Strategy: The phase currents have a common area of constant current value at top set point level.

The optimization of the ON/OFF angles is based in an iterative process, for each strategy (overlapping and no overlapping) and speed and current level:

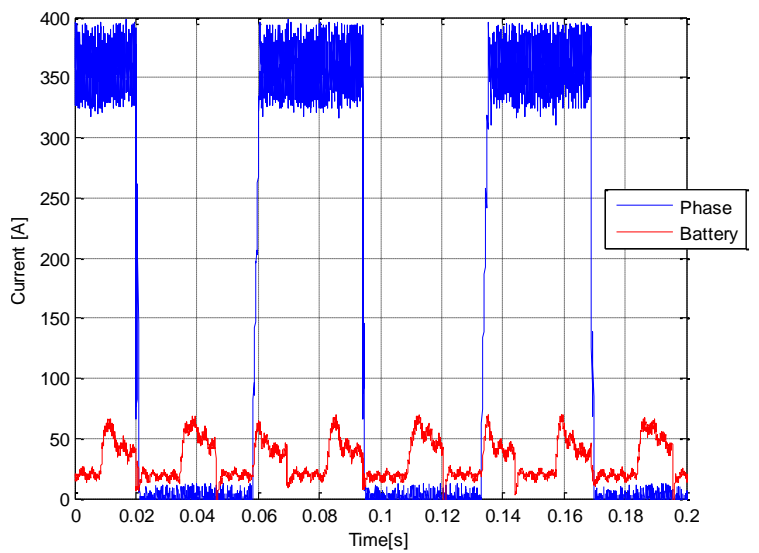

Fig. 16: U phase current waveform \& battery current waveform (@ Tem=1pu \& 100rpm)

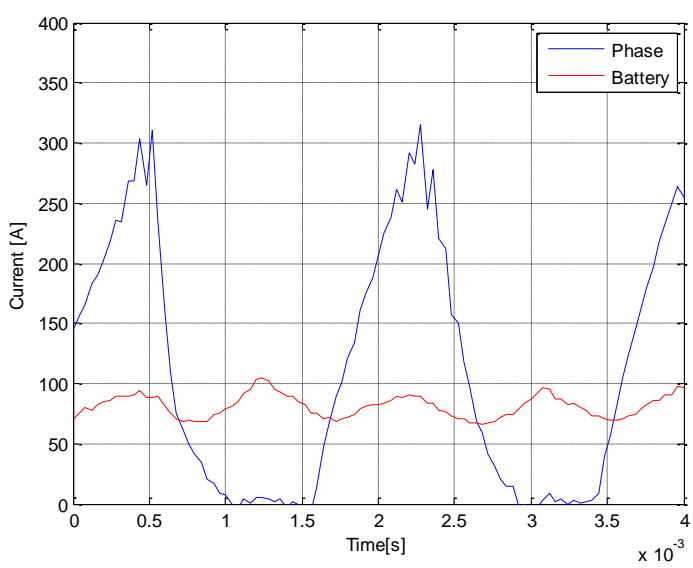

Fig. 17: U phase current waveform \& battery current waveform (@ Tem $=0.6 \mathrm{pu} \& 4000 \mathrm{rpm}$ )

1. The control is test with the theoretical ON/OFF values obtained from the simulations of the control design task.

2. An iterative adjustment of the ON/OFF angles is done around the initial values searching the maximum torque value per ampere.

3. The current waveform is checked. In case of high currents peaks, these angles are discarded going back to point 2 .

Next, some examples of the current shape with the optimized points for the non-overlapping strategy are shown in Fig. 16 and Fig. 17. For the overlapping strategy similar dynamic performances are obtained.

Once the on/off angles are optimized and the PI controller is set for low speeds, the dynamic performance of the machine is obtained as shown in Table 3. At low speed / low torque demand the system is able to give the desired torque but, at higher speeds and torque demand the given torque is reduced as predicted. 


\section{Workshop on SRM drives an alternative for E-traction}

TABle 3: MEASURED TORQUe (PU) AT DIFFERENT TORQUE REFERENCE SET-POINTS

\begin{tabular}{|c|c|c|c|c|c|}
\hline \%\rpm & $\mathbf{1 0 0}$ & $\mathbf{1 0 0 0}$ & $\mathbf{2 0 0 0}$ & $\mathbf{3 0 0 0}$ & $\mathbf{4 0 0 0}$ \\
\hline $\mathbf{2 0}$ & 0.21 & 0.21 & 0.20 & 0.20 & 0.2 \\
\hline $\mathbf{6 0}$ & 0.62 & 0.61 & 0.61 & 0.6 & 0.6 \\
\hline $\mathbf{1 0 0}$ & 1 & 0.98 & 0.90 & 0.78 & 0.6 \\
\hline
\end{tabular}

\section{CONCLUSIONS}

The results of the proposed torque control strategy which combines a torque feedback control for low speeds and a direct current consign generator for higher speeds show its validity.

At lower speeds where torque ripple may be critical, mostly when accelerating from zero speed a prominent ripple can lead to an uncomfortable driving experience due to vibrations. Even more critical may be when starting in a slope; the vehicle may go in reverse direction due to a negative torque caused by the ripple. This all is avoided as shown in the results using a PI control at low speeds.

At higher speeds the ripple vibration is not so noticeable by the vehicle occupants as the inertia may absorb it, so a direct current consign generation show to be enough.

The main difficulty of this control is that the characterization of the electrical machine will define the effectivity of the control. However, his work has shown that obtaining the torque and inductance characteristic of the machine is an easy task, leading to a proper control.

The optimal on/off switching angles calculated in simulation give a good reference for the experimental setting of the actual optimal switching points. However, these points must be slightly changed so the torque per ampere ratio is maximized.

\section{REFERENCES}

[1] Labak and N. C. Kar, "A novel five-phase pancake shaped switched reluctance motor for hybrid electric vehicles," Vehicle Power and Propulsion Conference, 2009. VPPC '09. IEEE, Dearborn, MI, 2009, pp. 494-499.

[2] A. Labak and N. C. Kar, "Designing and Prototyping a Novel Five-Phase Pancake-Shaped Axial-Flux SRM for Electric Vehicle Application Through Dynamic FEA Incorporating Flux-Tube Modeling," inIEEE Transactions on Industry Applications, vol. 49, no. 3, pp. 1276-1288, May-June 2013.

[3] Horacio Vasquez, Joey K Parker, A new simplified mathematical model for a switched reluctance motor in a variable speed pumping application, Mechatronics, Volume 14, Issue 9, November 2004, Pages 1055-1068, ISSN 0957-4158

[4] S. Smaka, S. Masic and M. Cosovic, "Fast analytical model of switched reluctance machine," Power Electronics Conference (IPEC-Hiroshima 2014 - ECCE-ASIA), 2014 International, Hiroshima, 2014, pp. 11481154.

[5] P. Lobato, S. Rafael, P. Santos and A. J. Pires, "Magnetic characteristics modelling for regular Switched Reluctance Machines: Analytical and FEM approaches," Power Engineering, Energy and Electrical Drives, 2009. POWERENG '09. International Conference on, Lisbon, 2009, pp. 60-65.

[6] B. Parreira, S. Rafael, A. J. Pires and P. J. C. Branco, "Obtaining the magnetic characteristics of an 8/6 switched reluctance machine: from FEM analysis to the experimental tests," in IEEE Transactions on Industrial Electronics, vol. 52, no. 6, pp. 1635-1643, Dec. 2005. doi: 10.1109/TIE.2005.858709
[7] H. Le-Huy and P. Brunelle, "A versatile nonlinear switched reluctance motor model in Simulink using realistic and analytical magnetization characteristics," Industrial Electronics Society, 2005. IECON 2005. 31st Annual Conference of IEEE, 2005, pp. 6 pp.

[8] F. Soares and P. J. Costa Branco, "Simulation of a 6/4 switched reluctance motor based on Matlab/Simulink environment," in IEEE Transactions on Aerospace and Electronic Systems, vol. 37, no. 3, pp. 989-1009, Jul 2001.

[9] Dong-Hee Lee (2011). Advanced Torque Control Scheme for the High Speed Switched Reluctance Motor, Advances in Motor Torque Control, Dr. Mukhtar Ahmad (Ed.), ISBN: 978-953-307-686-7, InTech, DOI: 10.5772/20701.

[10] Husain, "Minimization of torque ripple in SRM drives," in IEEE Transactions on Industrial Electronics, vol. 49, no. 1, pp. 28-39, Feb 2002.

[11] J. Peter, "Modeling \& Torque Ripple Minimization of Switched Reluctance Motor for High Speed Applications" International Journal of Science and Modern Engineering (IJISME) ISSN: 2319-6386, Volume-1, Issue-10, September 2013

[12] Jin Woo Lee, Hong Seok Kim, Byung Il Kwon and Byung Taek Kim, "New rotor shape design for minimum torque ripple of SRM using FEM," in IEEE Transactions on Magnetics, vol. 40, no. 2, pp. 754-757, March 2004.

\section{BIOGRAPHIES}

A. Egea received the degree in electrical engineering from the University of Mondragon, Mondragon, Spain, in 2009 and the $\mathrm{Ph} . \mathrm{D}$. degree in electrical engineering in 2012. Currently he is an Associated Professor in the Faculty of Engineering, University of Mondragon. His current research interests include electrical machine design and control and electromagnetic actuators.

Gaizka Ugalde received the B.S. and the Ph.D. degrees in electrical engineering from the University of Mondragón, Mondragón, Spain, in 2006and 2009, respectively. Since 2009, he has been with the Department of Electronics, Faculty of Engineering, University of Mondragón, where he is currently an Associate Professor. His current research interests includepermanent-magnet machine design, modeling, and control. He has participated in various research projects in the fields of lift drives and railway traction.

J. Poza was born in Bergara, Spain, in June 1975. He received the degree in electrical engineering from the University of Mondragon, Mondragon, Spain, in 1999, and the $\mathrm{Ph} . \mathrm{D}$. degree in electrical engineering from the Institut National Polytechniquede Grenoble, Grenoble, France. In 2002 he joined the Department of Electronics, Faculty of Engineering, University of Mondragon, where he is currently an Associate Professor. 